for the philosophy of mathematics. Precisely what he took these consequences to be is something that the reader has to work very hard to discover.

Wittgenstein's mode of composition was unique. He filled notebooks with 'remarks', a few lines in length, which he continually revised; he would also constantly rearrange the 'remarks' in different sequences to form a disjointedly continuous text. Sometimes the import of the individual remark is luminously clear, sometimes quite obscure: but the method of composition obviously risks leaving the sequence of thought difficult to follow. That it need not have this ef fect is apparent from the Investigations, the only product of his later period that Wittgenstein regarded as a (nearly) finished book: there the final product of years of revision and rearrangement provides a largely continuous treatment of a range of topics, and, given close concentration on the reader's part, expresses with considerable clarity Wittgenstein's conclusions concerning them. Unfortunately, such an outcome to so strange a mode of composition was usually attained only at the final stage: the present book contains seven different sequences of remarks, five of them with omissions made by the editors, and none of them representing a final stage. It is difficult to convey the obstacles which this presents to comprehension without extensive quotation, but perhaps the following brief sequence from Part IV may be regarded as not untypical:

37. A human being is imprisoned in a room, if the door is unlocked but opens inwards; he, however, never gets the idea of pulling instead of pushing against it.

38. When white turns black some people say "Essentially it is still the same"; and others, when the colour turns a shade darker: "It is completely different".

39. The proposition ' $a=a$ ', ' $p p$ ' ['If $p$, then $p$ '], 'The word "Bismark" has 8 letters', 'There is no such thing as reddish-green', are all obvious and are propositions about essence: what have they in common? They are evidently each of a different kind and differently used. The last but one is the most like an empirical proposition. And it can understandably be called a synthetic a priori proposition.

It can be said: unless you put the series of numbers and the series of letters side by side, you cannot know how many letters the word has.

Of course; no-one can be expected to understand the drift of such a sequence torn from its context: but it illustrates reasonably well the difficulties with which the reader has to contend. We have first two striking illustrations: but what exactly they are intended as illustrations of has to be gathered from the whole context in which they are embedded, bearing in mind that, if Wittgenstein had revised his text further, they might have been placed in a quite different immediate context, and bearing in mind also that what is printed here is only a selection, and the editors have not indicated where the omissions occur. There follows, in $\S 39$, what can only be described as a series of musings. None of the observations it contains can possibly be gainsaid: our difficulty is to know what force they have. The four propositions are indeed obvious: what connection is this supposed to have with their bearing 'about essence'? What relation do such propositions have to others that are equally 'about essence' but are not at all obvious? In saying that they are 'about essence', is Wittgenstein merely borrowing a term from another philosophy in order to express the priori character which anyone would be likely to see as attaching to all four propositions, or does he have a sharp idea of essence? Do the propositions have more in common than what has already been stated, namely that they are obvious and are about essence? They are evidently all different, and differently used: but how great are we supposed to see these differ-

\section{Geochemical handbook}

Handbook of Geochemistry. Vol.2, Part 5: Elements La (57) to U (92). Edited by K.M. Wedepohl. Pp.1546. (Springer: Berlin, Heidelberg and New York, 1979). Looseleaf binder DM690; \$379.50.

Four years have elapsed since the publication of Part 4 of the Handbook of Geochemistry, the longest gap in the production schedule, which has extended almost over a decade from 1969 to 1978 . Part 4 is also by far the largest to appear, comprising more than 1500 pages. The original intention of the editorial board was that Volume 2 of the Handbook would ultimately contain approximately 2000 pages in four instalments, with publication completed several years ago. The much larger compilation and considerably extended publication time no doubt reflect many factors, not least the rapid growth of geochemical literature and the fact that all authors contributing to the project did not work at the same rate.

The Handbook was probably never intended, even in early days, for the individual purchaser. It is expensive to buy, now costing on the subscription price $\$ 785.60$ (DM 1428.40), including Volume 1 , which contained a series of chapters on geochemistry, geophysics and cosmochemistry. Volume 2 is, however, the principal expense. The dollar price for each part has, not surprisingly, risen over the years, but the price in German marks for each part has been held to the level at time of publication.

What does the purchaser receive for his money? In Part 5 he is presented with the pages to complete a large number of the chapters on individual elements, some of which were begun almost a decade ago. Several of these elements, notably phosphorus, sulphur, titanium, chorium, manganese, cobalt, strontium and molyb- ences as being? The third proposition may understandably be called synthetic a priori: but can it justifiably be so called? To obtain any philosophical illumination from a passage like this, the reader must answer all these questions and more: and he must answer them not only to his own satisfaction, but in the manner that it is plausible that Wittgenstein intended them to be answered. As Frege said of his own posthumously published writings, not all of what is contained in this book is gold, but there is gold in it: but, in Wittgenstein's case, the mining operation is particularly arduous.

Michael Dummett

Michael Dummett is Fellow of All Souls College, Oxford, UK.

denum, are important geochemically, and virtually no information has been available for these elements until now in the Handbook. Although this lack of data has at times been frustrating, at least there is now the compensation that these chapters are the most up-to-date in the book. Many new pages carrying amendments that include additional information and the correction of scientific and printing errors, are also supplied with Part V.

Of the Handbook as a whole, once rearrangement of the entire loose-leaf system - not really a drawback, despite editorial concern - has been completed, the text represents the most comprehensive compilation of geochemical data so far attempted in one publication. The Handbook is logical in lay-out, with a high publishing standard of text (and the many tables and diagrams) maintained throughout. As more than 100 authors have been involved in the project, it is inevitable that the style, presentation and depth of coverage between, and even within, chapters will vary. The reader will have to accept this lack of uniformity, just as he will have to accept that much of the text is not up-todate - the first manuscript was received in 1965. The editorial board now accepts that revision of earlier text to include more recent information is impossible, whatever its members might have felt individually or collectively in the euphoria at the start of the project. They must be relieved it is all over and it is perhaps unlikely that any one of them will embark again on such a largescale project. The editors and authors should receive the congratultions and thanks of geochemists, first for successfully completing the Handbook and second for providing such a valuable authoritative base of data that will make the geochemist's professional life so much easier.

D.G. Murchison

D.G. Murchison is Professor of Organic Petrology and Past Reader in Geochemistry at the University of Newcastle-upon-Tyne, UK. 